Pacific Journal of Mathematics

A RADICAL COINCIDING WITH THE LOWER RADICAL IN YT 


\title{
A RADICAL COINCIDING WITH THE LOWER RADICAL IN ASSOCIATIVE AND ALTERNATIVE RINGS
}

\author{
W. G. LeavitT AND Yu-Lee LeE
}

\begin{abstract}
In a recent paper by the second author a construction was given which was shown to coincide with the lower radical in all associative rings. In the present paper this construction is considered in various classes of not necessarily associative rings. It is shown that while the construction still defines a radical, it will in general properly contain the lower radical. More precisely, it is shown that the radical constructed coincides with the lower radical if the semisimple class of the lower radical is hereditary (or, equivalently, if the radical of a ring always contains the radicals of all its ideals).
\end{abstract}

From this condition it follows that the construction coincides with the lower radical in all associative and alternative rings, but an example is given which shows that this is not true in general. We conclude by showing that an apparently quite different construction due to J.F. Watters [5] yields exactly the same class of rings.

We will assume that all rings considered in this paper are from some universal class $\mathscr{U}$ of not necessarily associative rings. We will use the following construction, which is equivalent to that of [4]. Let $\mathscr{A}$ be an arbitrary class of rings and $\mathscr{A}_{0}$ its homomorphic closure. Then define $\mathscr{A}_{n}=\left\{R \in \mathscr{U} \mid R\right.$ has a nonzero ideal $\left.I \in \mathscr{A}_{n-1}\right\}$, and $A_{\omega}=$ $\mathrm{U}_{n} \mathscr{A}_{n}$. Then define $\mathscr{Y}(\mathscr{A})=\left\{R \in \mathscr{U} \mid R / I \in \mathscr{A}_{\omega}\right.$ for all ideals $I$ of $\left.R\right\}$. It is clear from this definition that we have

Lemma $1 . \mathscr{A} \cong \mathscr{A}_{0} \subseteq \mathscr{Y}(\mathscr{A})$.

Lemma 2. $\mathscr{A} \cong \mathscr{B}$ implies $\mathscr{Y}(\mathscr{A}) \subseteq \mathscr{Y}(\mathscr{B})$.

It is also easy to check that the proof of [4, Th. 1] makes no use of associativity. Thus we may state

THEOREM 1. $\mathscr{Y}(\mathscr{A})$ is a radical class.

We will replace [4, Th. 2] by the following generalization:

THEOREM 2. If $\mathscr{P}$ is a radical sub-class of $\mathscr{U}$, then $\mathscr{P}=\mathscr{Y}(\mathscr{P})$ if either of the following two equivalent conditions is satisfied:

(i) The semisimple class $\mathscr{S} \mathscr{P}$ of $\mathscr{P}$ is hereditary,

(ii) Writing $\mathscr{P}(R)$ for the $\mathscr{P}$-radical of $R$, then $\mathscr{P}(I) \subseteq \mathscr{P}(R)$ 
for every ideal $I$ of every $R \in \mathscr{U}$.

Proof. The equivalence of (i) and (ii) follows from [1, Lemma 2, p. 595]. Thus assume that $\mathscr{S} \mathscr{P}$ is hereditary. By Lemma 1 we have $\mathscr{P} \subseteq \mathscr{Y}(\mathscr{P})$ and suppose there could exist $R \in \mathscr{Y}(\mathscr{P}), R \in \mathscr{P}$. Then $R$ has a nonzero homomorphic image in $\mathscr{S} \mathscr{P}$, so (without loss of generality) assume $R \in \mathscr{Y}(\mathscr{P}) \cap \mathscr{S} \mathscr{P}$. Thus $R \in \mathscr{P}_{n}$ for some $n$, and since $\mathscr{P} \cap \mathscr{S} \mathscr{P}=0$ it is clear that $n \geqq 1$. Let $m$ be the smallest integer such that there exists a nonzero $R \in \mathscr{P}_{m} \cap \mathscr{S} \mathscr{P}$. Then $R$ has a nonzero ideal $I \in \mathscr{P}_{m-1}$. Since $\mathscr{S} \mathscr{P}$ is hereditary $I \in \mathscr{S} \mathscr{P}$ contrary to the minimality of $m$. Thus $\mathscr{P}=\mathscr{Y}(\mathscr{P})$.

CoRollary 1. If $\mathscr{P}$ is a radical class then in any associative or alternative ring the $\mathscr{P}$-radical and the $\mathscr{Y}(\mathscr{P})$-radical coincide.

Proof. This is clear since the intersection of $\mathscr{P}$ with any universal associative or alternative class is again a radical class and semisimple classes are always hereditary in associative [2, Corollary 2, p. 125] or alternative classes [1, Corollary 2, p. 602].

Note that a sufficient condition for property (ii) is that $\mathscr{P}(I)$ shall be an ideal of $R$. This is already known to be true in associative rings [2, Th. 47, p. 124] or alternative rings [1, Th. 2, p. 600]. From this last remark it also follows that the proof of [4, Th. 2] could have been applied equally well to alternative rings.

THEOREM 3. Let $\mathscr{L}(\mathscr{A})$ be the lower radical for an arbitrary class $\mathscr{A}$. Then $\mathscr{L}(\mathscr{A})=\mathscr{Y}(\mathscr{A})$ if $\mathscr{S} \mathscr{L}(\mathscr{A})$ is hereditary.

Proof. Suppose $\mathscr{S} \mathscr{L}(\mathscr{A})$ is hereditary. From Lemma 1 and the minimality of $\mathscr{L}(\mathscr{A})$ among radical classes containing $\mathscr{A}[2$, Lemma 5, p. 13] it follows that $\mathscr{L}(\mathscr{A}) \subseteq \mathscr{Y}(\mathscr{A})$. But by Lemma $2, \mathscr{A} \cong \mathscr{L}(\mathscr{A})$ implies $\mathscr{Y}(\mathscr{A}) \subseteq \mathscr{Y}(\mathscr{L}(\mathscr{A}))$. Then if $\mathscr{S} \mathscr{L}(\mathscr{A})$ is hereditary if follows from Theorem 2 that $\mathscr{Y}(\mathscr{L}(\mathscr{A}))=\mathscr{L}(\mathscr{A})$ and so $\mathscr{L}(\mathscr{A})=\mathscr{Y}(\mathscr{A})$.

We can thus conclude that the $\mathscr{Y}(\mathscr{A})$-radical coincides with the lower radical in any associative or alternative ring.

Note. The class $\mathscr{I}$ of all idempotent rings is a radical class whose semisimple class is nonhereditary [3, Th. 2, p. 1116]. It is also true that $\mathscr{Y}(\mathscr{J})=\mathscr{J}$ for if $R \notin \mathscr{F}$ then since all subrings of $R / R^{2}$ are zero rings, $R / R^{2}$ has no accessible subrings in $\mathscr{F}$. Thus $R \notin \mathscr{Y}(\mathscr{F})$ and so $\mathscr{Y}(\mathscr{J})=\mathscr{F}$. This example shows that the conditions of Theorems 2 and 3 are not necessary.

Also remark that there are classes $\mathscr{A}$ for which $\mathscr{Y}(\mathscr{A})$ is not the lower radical. One example is the class $\mathscr{B}=\mathscr{L}(\mathscr{Z})$ where $\mathscr{Z}$ 
is the class of all zero rings. Let $R$ be the ring constructed [see 3] over $Z_{2}$ in symbols $u, v, w$ satisfying relations $u^{2}=w^{2}=0, u v=v u=$ $u w=u$, and $w u=v w=w v=v^{2}=v$. The only ideal of $R$ is $H=$ $\{0, u, v, u+v\}$ for which $H^{2}=H$. Now $\mathscr{J}$ is a hereditary class so by a result of A.E. Hoffman [see 6, Theorem 1,] we have $\mathscr{I} \cap \mathscr{L}(\mathscr{L})=0$. Now the lower radical of a hereditary class is hereditary. Thus $\mathscr{L}(\mathscr{L})$ is hereditary and so $R \notin \mathscr{L}(\mathscr{F})$. On the other hand, $R / H \in \mathscr{Z}$ and $R$ has the accessible subring $J=\{0, u\} \in \mathscr{Z}$. Hence $R \in \mathscr{Y}(\mathscr{Z})$.

It should also be noted that while $\mathscr{Y}(\mathscr{A})$ need not equal $\mathscr{L}(\mathscr{A})$, it is nevertheless true for all classes $\mathscr{A}$ that $\mathscr{Y}(\mathscr{L}(\mathscr{A}))=\mathscr{Y}(\mathscr{A})$. This is an easy consequence of the fact that $\mathscr{Y}(\mathscr{Y}(\mathscr{A}))=\mathscr{Y}(\mathscr{A})$.

In a paper [5] which is soon to appear the following construction is given: Let $\mathscr{C l}$ be an arbitrary homomorphically closed subclass of some universal class $\mathscr{U}$. For $R \in \mathscr{C}$ define $M_{\sigma 0}=0$, and for an arbitrary ordinal $\alpha \quad M_{\sigma \alpha}=\bigcup_{\beta<\alpha} M_{\sigma \beta}$, if $\alpha$ is a limit ordinal, or $M_{\sigma \alpha} / M_{\sigma \beta}$ is the ideal of $R / M_{\sigma \beta}$ generated by all accessible $\mathscr{C}$-subrings of $R / M_{\sigma \beta}$, whenever $\alpha=\beta+1$. If $\gamma$ is the ordinal for which $M_{\sigma \zeta}=$ $M_{\sigma_{\gamma+1}}$, write $M_{\sigma}(R)=M_{\sigma_{\zeta}}$ and let $\mathscr{C}_{\sigma}^{\prime}=\left\{R \in \mathscr{U} \mid M_{\sigma}(R)=R\right\}$.

\section{Theorem 4. $\mathscr{C l}_{\sigma}^{\prime}=\mathscr{Y}(\mathscr{C l})$.}

Proof. Let $R$ be a ring for which $M_{\sigma}(R)=R$, and let $I \neq R$ be an ideal of $R$. Then $0=M_{\sigma 0} \leqq I$, and there must exist some ordinal $\alpha$ such that $M_{\sigma \alpha} \leqq I$ but $M_{\sigma \alpha+1} \nsubseteq I$. Write $A=M_{\sigma \alpha}, B=M_{\sigma \alpha+1}$. Since $I$ is an ideal of $R$, it follows from the definition that $B / A$ contains an accessible $\mathscr{C}$-subring $W / A$ of $R / A$ such that $W \nsubseteq I$. Then the natural homomorphism $R / A \rightarrow R / I$ gives $W / A \rightarrow W^{\prime}$ with $W^{\prime}$ accessible. Thus since $\mathscr{C}$ is homomorphically closed, we have a nonzero $W^{\prime} \in \mathscr{C}$. It follows that $R / I \in \mathscr{A}_{n}$ for some $n$ and since $I$ was arbitrary, $R \in \mathscr{Y}(\mathscr{C l})$. Thus $\mathscr{K}_{\sigma}^{\prime} \subseteq \mathscr{Y}(\mathscr{C})$.

The converse is clear, for suppose $R \in \mathscr{Y}(\mathscr{C})$ and $I=M_{\sigma}(R)=$ $M_{\sigma \zeta}(R)$. If $I \neq R$, it follows that $R / I$ has an accessible $\mathscr{C}$-subring, contradicting $M_{\sigma \gamma}(R)=M_{\sigma \zeta+1}(R)$. Thus $M_{\sigma}(R)=R$ whence $R \in \mathscr{C l}_{\sigma}^{\prime}$ and so $\mathscr{C l}_{\sigma}^{\prime}=\mathscr{Y}(\mathscr{C})$.

\section{REFERENCES}

1. T. Anderson, N. Divinsky, and A. Sulinski, Hereditary radicals in associative and alternative rings, Canad. J. Math. 17 (1965), 594-603.

2. N. J. Divinsky, Rings and radicals, Univ. of Toronto Press, 1965.

3. W. G. Leavitt and E. P. Armendariz, Nonhereditary semisimple classes, Proc. Amer. Math. Soc. 18 (1967), 1114-1117.

4. Yu-Lee Lee, On the construction of lower radical properties, Pacific J. Math. 28 (1969), 393-395. 
5. J. F. Watters, Lower radicals in associative rings, Canad. J. Math. 21 (1969), 466476.

6. A. E. Hoffman and W. G. Leavitt, Properties inherited by the lower radical, Port, Math. (to appear).

Received May 23, 1968.

University of NebRASKa

Kansas State University 


\title{
PACIFIC JOURNAL OF MATHEMATICS
}

\author{
EDITORS
}

H. ROYDEN

Stanford University

Stanford, California

R. R. PhelPS

University of Washington

Seattle, Washington 98105
J. DUGUNDJI

Department of Mathematics

University of Southern California

Los Angeles, California 90007

RICHARD ARENS

University of California

Los Angeles, California 90024

\section{ASSOCIATE EDITORS}
E. F. BECKENBACH
B. H. NeumanN
F. WOLF
K. YoSHIDA

\section{SUPPORTING INSTITUTIONS}

\author{
UNIVERSITY OF BRITISH COLUMBIA \\ CALIFORNIA INSTITUTE OF TECHNOLOGY \\ UNIVERSITY OF CALIFORNIA \\ MONTANA STATE UNIVERSITY \\ UNIVERSITY OF NEVADA \\ NEW MEXICO STATE UNIVERSITY \\ OREGON STATE UNIVERSITY \\ UNIVERSITY OF OREGON \\ OSAKA UNIVERSITY \\ UNIVERSITY OF SOUTHERN CALIFORNIA
}

\author{
STANFORD UNIVERSITY \\ UNIVERSITY OF TOKYO \\ UNIVERSITY OF UTAH \\ WASHINGTON STATE UNIVERSITY \\ UNIVERSITY OF WASHINGTON \\ $\stackrel{*}{*} \stackrel{*}{*}{ }^{*}{ }^{*}$ \\ CHEVRON RESEARCH CORPORATION \\ TRW SYSTEMS \\ NAVAL WEAPONS CENTER
}

The Supporting Institutions listed above contribute to the cost of publication of this Journal, but they are not owners or publishers and have no responsibility for its content or policies.

Mathematical papers intended for publication in the Pacific Journal of Mathematics should be in typed form or offset-reproduced, double spaced with large margins. Underline Greek letters in red, German in green, and script in blue. The first paragraph or two must be capable of being used separately as a synopsis of the entire paper. It should not contain references to the bibliography. Manuscripts, in duplicate if possible, may be sent to any one of the four editors. Please classify according to the scheme of Math. Rev. 36, 1539-1546. All other communications to the editors should be addressed to the managing editor, Richard Arens, University of California, Los Angeles, California, 90024.

50 reprints are provided free for each article; additional copies may be obtained at cost in multiples of 50 .

The Pacific Journal of Mathematics is published monthly. Effective with Volume 16 the price per volume (3 numbers) is $\$ 8.00$; single issues, $\$ 3.00$. Special price for current issues to individual faculty members of supporting institutions and to individual members of the American Mathematical Society: $\$ 4.00$ per volume; single issues $\$ 1.50$. Back numbers are available.

Subscriptions, orders for back numbers, and changes of address should be sent to Pacific Journal of Mathematics, 103 Highland Boulevard, Berkeley, California, 94708.

PUBLISHED BY PACIFIC JOURNAL OF MATHEMATICS, A NON-PROFIT CORPORATION

Printed at Kokusai Bunken Insatsusha (International Academic Printing Co., Ltd.), 7-17, Fujimi 2-chome, Chiyoda-ku, Tokyo, Japan. 


\section{Pacific Journal of Mathematics \\ Vol. 30, No. $2 \quad$ October, 1969}

Gregory Frank Bachelis, Homomorphisms of annihilator Banach algebras.

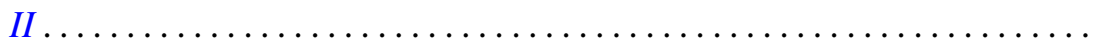

Leon Bernstein and Helmut Hasse, An explicit formula for the units of an algebraic number field of degree $n \geq 2 \ldots \ldots \ldots \ldots \ldots \ldots \ldots . \ldots 29$

David W. Boyd, Best constants in a class of integral inequalities ........ 367

Paul F. Conrad and John Dauns, An embedding theorem for lattice-ordered

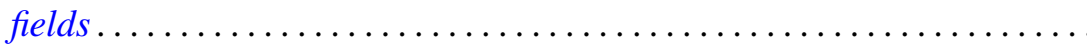

H. P. Dikshit, Summability of Fourier series by triangular matrix

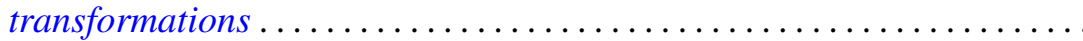

Dragomir Z. Djokovic, Linear transformations of tensor products preserving a fixed rank............................. 411

John J. F. Fournier, Extensions of a Fourier multiplier theorem of Paley . . . 415 Robert Paul Kopp, A subcollection of algebras in a collection of Banach

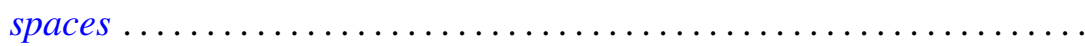

Lawrence Louis Larmore, Twisted cohomology and enumeration of vector bundles ...................................... 437

William Grenfell Leavitt and Yu-Lee Lee, A radical coinciding with the lower radical in associative and alternative rings .................

Samuel Merrill and Nand Lal, Characterization of certain invariant subspaces of $H^{p}$ and $L^{p}$ spaces derived from logmodular

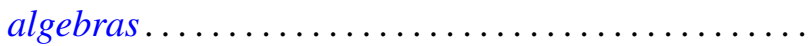

Sam Bernard Nadler, Jr., Multi-valued contraction mappings ....

T. V. Panchapagesan, Semi-groups of scalar type operators in Banach spaces ....................................

J. W. Spellmann, Concerning the infinite differentiability of semigroup motions

H. M. (Hari Mohan) Srivastava, A note on certain dual series equations involving Laguerre polynomials.

Ernest Lester Stitzinger, A nonimbedding theorem of associative algebras................................

J. Jerry Uhl, Jr., Martingales of vector valued set functions ...

John Mays Worrell Jr., On continuous mappings of metacompact $\check{C} e c h$

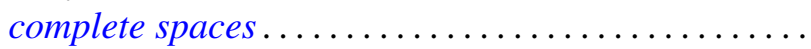

